\title{
Gastrointestinal parasites of captive Asian elephants in Kerala*
}

\author{
M.S. Punya ${ }^{1 *}$, V.H. Shyma ${ }^{2}$, V.C. Reshnu ${ }^{3}$, K. Vijayakumar ${ }^{4}$, K. Vinodkumar ${ }^{2}$, \\ R. Ambily ${ }^{5}$ and Arun Zachariah ${ }^{6}$ \\ Department of Veterinary Epidemiology and Preventive Medicine, \\ College of Veterinary and Animal Sciences, Mannuthy, Thrissur- 680651 \\ Kerala Veterinary and Animal Sciences University, Kerala, India.
}

Citation: Punya, M.S., Shyma, V.H., Reshnu, V.C, Vijayakumar, K., Vinodkumar, K., Ambily, R. and Arun Zachariah. 2021. Gastrointestinal parasites of captive Asian elephants in Kerala. J. Vet. Anim. Sci. 52(3): 312-315. DOI: https://doi.org/10.51966/jvas.2021.52.3.312-315

Received:01.03.2021

Accepted: 26.06.2021

Published: 30.09 .2021

\begin{abstract}
Gastrointestinal parasitic infections invariably affect the health status of elephants and can cause disease and death in elephants. This study was conducted to assess the incidence of gastrointestinal (Gl)parasitesof elephants in Kerala and to relate it to the deworming status. A total of 31 Asian elephants presented to the Teaching Veterinary Clinical Complex, Mannuthy, those under private ownership (Thrissur) and forest department formed the basis of the study.It was observed that 32.2 per cent of elephants in the study were affected with GI parasites. High percentage of strongyle ova was observed followed by the mixed infection of strongyle and Strongyloides ova. Statistical analysis of haematological parameters were done by using student $t$ test in SPSS version 24.0. The haematological studies of elephants infected with GI parasites revealed anaemia and eosinophilia.
\end{abstract}

Keywords: Elephant, gastrointestinal parasites, Kerala

Elephants are enlisted as endangered species by the World Conservation Union. Many factors like poaching, habitat loss, fragmentation and disease outbreaks were considered as threatening factors (Riddle et al. 2010). Apart from that,parasitism affects the elephant's health,

*Part of MVSc thesis submitted to Kerala Veterinary and Animal Sciences University, Pookode, Wayanad, Kerala

1. MVSc Scholar

2. Assistant Professor

3. Emergency Veterinary Officer, Nedumangad block

4. Professor and Head

5. Assistant Professor, Department of Veterinary Microbiology

6. Forest Veterinary Officer, Wayanad

${ }^{* * C}$ Corresponding author:email:punya25sree@gmail.com, Ph: 8281365799

Copyright: (c) 2021 Punya et al. This is an open access article distributed under the terms of the Creative Commons Attribution 4.0 International License (http://creativecommons.org/licenses/by/4.0/), which permits unrestricted use, distribution, and reproduction in any medium, provided the original author and source are credited.

312 Gastrointestinal parasites of elephants in Kerala... 
fertility, behaviour and which facilitates parasite transmission.Several factors which determine the parasitic transmission include environmental conditions affecting the viability and behaviour of parasite ova, feeding, movementand defecation patterns of the host (Vidya and Sukumar, 2002). Helminthic infections were considered to be a major problem as it can cause mortality in captive animals (Borghareet al., 2009). Damp unhygienic conditions and small enclosures for captive and semi-captive elephants predispose them to gastrointestinal parasitic infection (Chandrasekharanet al. 1995). The risk of parasitic infection in both wild and captive animals can be reduced by quantitatively assessing the parasitic load. This study reports the prevalent GI parasites among elephants in Kerala and attempts to relate the incidence with the deworming status.

Dung samples were collected from 31 Asian elephants in the age group ranging from three months to 70 yearsof both sexes directly from the ground during November 2019 to December 2020.After procurement, the faecal samples were stored in a zip lock cover, kept at $4^{\circ} \mathrm{C}$ and examined within $24 \mathrm{~h}$. Dung samples were examined by direct, sedimentation and floatation techniques in the department of Veterinary Epidemiology and Preventive Medicine as per Soulsby(1982). About $2 \mathrm{ml}$ of whole blood was collected in an EDTA vial and analysedusingAutomatic Haematology
Analyzer (Orphee, Mythic Vet 18) in the Teaching Veterinary Clinical Complex (TVCC).

Microscopical examination of dung samples from 31 Asian elephants revealed the presence of strongyle ova in seven (22.6 per cent) cases andStrongyloidesova in three (9.7 per cent) cases. The strongyle ova were observed as thin shelled with embryonated egg inside (Fig. 1). Strongyloides ova wasobserved as thin shelled ova with larva inside (Fig. 2\&3) All the elephants were regularly dewormed with fenbendazole at a dose rate of 5-10 $\mathrm{mg} / \mathrm{kg}$ Dung sample examination revealed high percentage for strongyle ova than Strongyloides. This finding is similar to that of Abhijithet al. (2018) who reported 58.1 per cent prevalence of strongyles in elephants from South Wayanad Forest Division of Kerala and suggested that the increased prevalence of strongyles was an indicative of potential transmission of parasites via faecal route. Vidya and Sukumar (2002) had reported mixed infection in a study conducted on intestinal parasites in Asian elephants (Elephasmaximus) of Southern India. Several genera of strongyles like Murshidia, Equinurbia, Choniangium, Quilonia, Bunostomum, Grammocephalusetc. are recorded in Asian elephants (Shahi and Gairhe,2019).However, molecular tools are needed for species identification from faecal samples. Out of the 31 dung samples, none were found to be positive for trematode or cestode

Table1. Haematological profile for elephants with parasitic load

\begin{tabular}{|c|c|c|c|}
\hline \multirow[b]{2}{*}{ Parameter } & \multicolumn{2}{|c|}{ Mean \pm SE } & \multirow[b]{2}{*}{ t- value } \\
\hline & $\begin{array}{c}\text { With GI parasites } \\
n=7\end{array}$ & $\begin{array}{l}\text { Without GI parasites } \\
\qquad n=24\end{array}$ & \\
\hline Total leucocytes count (x103/mm & $14.9 \pm 1.06$ & $14.09 \pm 1.47$ & $0.288^{\text {ns }}$ \\
\hline Lymphocytes (per cent) & $28.79 \pm 2.72$ & $28.41 \pm 2.58$ & $0.075^{\text {ns }}$ \\
\hline Monocytes (per cent) & $16.23 \pm 2.37$ & $15.19 \pm 1.51$ & $0.338^{\text {ns }}$ \\
\hline Granulocytes (per cent) & $57.41 \pm 3.52$ & $56.13 \pm 3.22$ & $0.114^{*}$ \\
\hline Total erythrocyte count $\left(\mathrm{x} 10^{6} / \mathrm{mm}^{3}\right)$ & $2.18 \pm 0.13$ & $3.25 \pm 0.19$ & $0.773^{*}$ \\
\hline Haemoglobin (g/dl) & $10.76 \pm 0.6$ & $11.76 \pm 0.74$ & $0.711^{\mathrm{ns}}$ \\
\hline Haematocrit (per cent) & $31.84 \pm 1.93$ & $33.92 \pm 2.36$ & $0.458^{\text {ns }}$ \\
\hline MCV (fl) & $107.3 \pm 6.43$ & $104.24 \pm 2.98$ & $0.470^{\text {ns }}$ \\
\hline $\mathrm{MCH}(\mathrm{pg})$ & $36.11 \pm 1$ & $36.28 \pm 0.83$ & $0.103^{\text {ns }}$ \\
\hline $\mathrm{MCHC}$ (per cent) & $34.81 \pm 3.12$ & $35.35 \pm 1.3$ & $0.184^{\text {ns }}$ \\
\hline Platelet count $\left(\times 10^{3} / \mathrm{mm}^{3}\right)$ & $360.43 \pm 16.97$ & $514.42 \pm 59.51$ & $2.489^{* *}$ \\
\hline
\end{tabular}

$p<0.01$; highly significant ${\left({ }^{* *}\right)}^{p}<0.05$; significant $\left(^{*}\right) p>0.05$; non-significant (ns) 


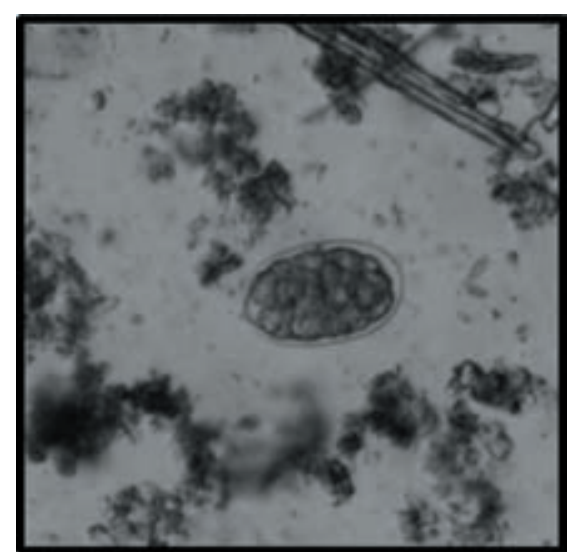

Fig.1. Strongyle ova

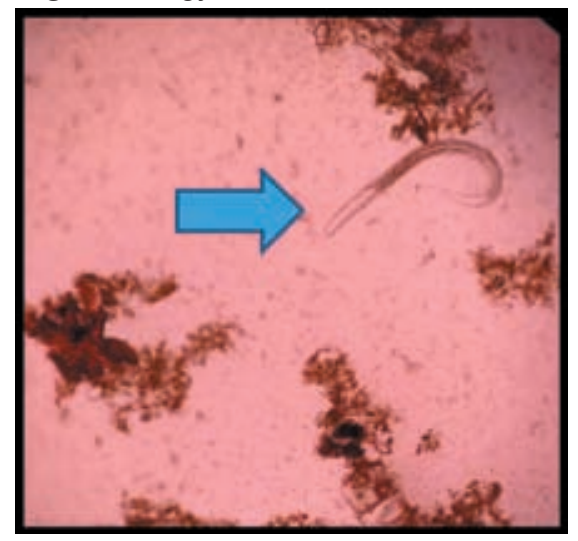

Fig.3. Strongyloides larva

ova. Amulya, (2016)identified Anoplocephala spp. (cestode) and Bivitellobilharzianairi (trematode) in Kerala.In Gujarat,Jani (2008) had found Fasciolaspp. to be more prevalent in elephants that had access to water bodies and a habit of soil licking. The 31 captive and semicaptive elephants included in the study had no access to water bodies but had a habit of soil licking.

Regular deworming is considered to be the main reason for the reduced presence of gastrointestinal parasite in the captive and semi-captive elephants. The captive and semicaptive elephants in Kerala were dewormed at an interval of 4 months after checking the faecal sample. Fenbendazole is a broad spectrum anthelmintic used against gastrointestinal parasites like Giardia, round worms, strongyles, etc. for captive elephants (Tiwari and Rao, 1996). In captive and semi-captive elephants, parasitic infection may aggravate because of space limitation as they were confined

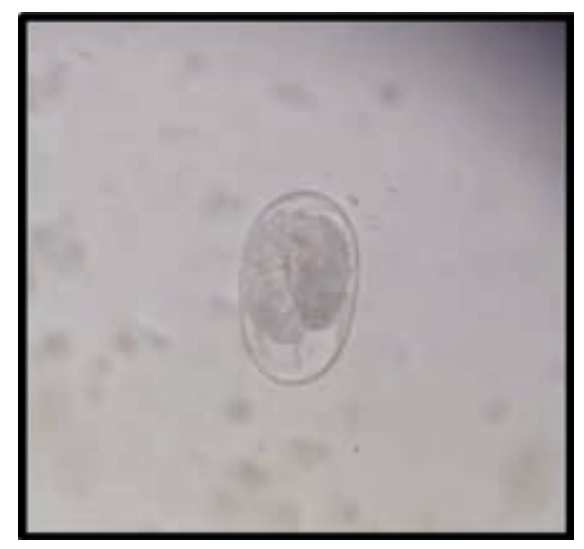

Fig. 2. Strongyloides ova

in close proximity (Abeysekaraet al., 2018). Saseendranet al.(2003)reported that 10 per cent captive elephants in Kerala, that were dewormed annually had strongyle infection.

The haematological parameters of elephants infected by helminth parasites were compared to that of apparently healthy elephants (Table1). Significant low levels of total erythrocyte count $\left(2.18 \pm 0.13 \times 10^{6} /\right.$ $\left.\mathrm{mm}^{3}\right)$ and haemoglobin $(10.76 \pm 0.6 \mathrm{~g} / \mathrm{dl})$ as well as significant high levels of granulocytes (57.41 \pm 3.52 per cent) were noticed in elephants harbouring parasites. Haematological findings suggestive of anaemia is in agreement with Sarodeet al. (1991) who also reported low significant reduction in both erythrocyte count and haemoglobin in elephants due to helminth infection. Significant eosinophilia $(57.41 \pm 3.52$ per cent)could be observed in the affected animals and it can be due to hypersensitivity reaction towards parasites as observed by Jani(2008).

\section{Summary}

The effectiveness of deworming depends on the environmental conditions affecting viability and behaviour of the parasite ova, feeding, movement and defecation patterns of the host. Therefore, management practices play a significant role in reducing parasitic infection. Further studies on gastrointestinal parasites in Asian elephants of Kerala is essential to find out the presence of other nematodes, cestodes and flukes as reported from other state of India. 


\section{Acknowledgement}

The authors are thankful to Kerala Veterinary and Animal Sciences University and Kerala Forest and Wildlife Department for providing all facilities for the completion of this work.

\section{Conflict of interest}

The authors declare that they have no conflict of interest.

\section{References}

Abhijith, T.V., Mohanarangan, A., Rons, T.D. and Chandy, G. 2018. Gastrointestinal parasites of Asian elephants (Elephasmaximus L. 1798) in south Wayanad forest division, Kerala, India. J. Parasit. Dis. 42: 382-390.

Abeysekara, N., Rajapkse, R.P.V.J. and Rajakaruna, R.S. 2018. Comparative cross-sectionalsurveyongastrointestinal parasites of captive, semi-captive, and wild elephants of Sri Lanka. J. Threat. Taxa.10(5): 11583-11594.

Amulya, V.R. 2016.Screening and therapeutic management of parasitic infections in captive asian elephants (Elephasmaximusindicus). M.V.Sc thesis, Kerala Veterinary and Animal Sciences University, Pookode, 60p.

Borghare, A.T., Bagde, V.P., Jaulkar, A.D., Katre, D.D., Jamde, P.D.,Maske, D.K. and Bhangale, G.N. 2009.Incidence of gastrointestinal helminthiasisof captive wild deers at Nagpur. Vet.World.2(9):337338.

Chandrasekharan, K., Radhakrishnan, K., Cheeran, J.V., Muraleedharan, K.N. and Prabhakaran, T. 1995. Review of the incidence, etiology and control of common diseases of Asian elephants with special reference to Kerala, pp. 439449. In: Daniel J.C. \& H.S. Datye (eds.).

A Week with Elephants.International Seminar on the Conservation of Elephant, India.
Jani, R.G. 2008.Prevalence and HaematoBiochemical Studies of Gastrointestinal Parasites of Indian Elephants (Elephasmaximus).Vet.World.1(10): 296-298.

Riddle, H.S., Schulte, B.A., Desai, A.A. and Meer, L.V.D. 2010. Elephants: a conservation overview. J. Threat. Taxa.2: 653-66.1

Sarode, D.B., Hatwar, A.K. and Hiwase, S.D. 1991. Helminth infection with reference to the clinical and haematological observations in elephants.Zoos' PrintJ. VI (11): 10-11

Saseendran, P.C., Rajendran, S., Subramanian, H., Sasikumar, M., Vivek, G. and Anil, K.S. 2003. Incidence of helminthic infection among annually dewormed captive elephants. Zoos' Print J. 19(3): 1422.

Shahi, M.K. and Gairhe, K.P, 2019. Prevalence of Helminths in Wild Asian Elephant and Indian Rhinoceros in Chitwan and Bardia National Park, Nepal. Nepalese Vet. J. 36: 60-74.

Soulsby, E. J. 1982. Helminths.Arthropods and Protozoa of Domestic Animals, ELBS, BailliereTindall, London, 809pp.

Tiwari, S.P. and Rao, K.N.P. 1996. Fenbendazole - a useful dewormer for elephants. Zoos' PrintJ.9(4): 2-5.

Vidya, T.N.C and Sukumar, R. 2002. The effect of some ecological factors on the intestinal parasite loads of the Asian elephant (Elephasmaximus) in southern India. J. Biosci. 27: 521-528. 